\title{
Mutations in PTF 1A are not a common cause for human VATER/VACTERL association or neural tube defects mirroring Danforth's short tail mouse
}

\author{
NIRMALA GURUNG ${ }^{1 *}$, GRETA GROSSE$^{2 *}$, MARKUS DRAAKEN $^{2,3}$, \\ ALINA C. HILGER ${ }^{2}$, NUZHAT NAUMAN $^{4}$, ANDREAS MÜLLER $^{5}$, ULRICH GEMBRUCH ${ }^{6}$, \\ WALTRAUT M. MERZ ${ }^{6}$, HEIKO REUTTER ${ }^{2,5}$ and MICHAEL LUDWIG ${ }^{1}$

\begin{abstract}
${ }^{1}$ Department of Clinical Chemistry and Clinical Pharmacology; ${ }^{2}$ Institute of Human Genetics, University of Bonn; ${ }^{3}$ Department of Genomics, Life \& Brain Center, University of Bonn, Bonn D-53127, Germany; ${ }^{4}$ Department of Pathology, Holy Family Hospital, Rawalpindi 46000, Pakistan; ${ }^{5}$ Department of Neonatology, Children's Hospital, University of Bonn; ${ }^{6}$ Department of Obstetrics and Prenatal Medicine, University of Bonn, Bonn D-53127, Germany
\end{abstract}

Received May 26, 2014; Accepted February 27, 2015

DOI: $10.3892 / \mathrm{mmr} .2015 .3486$

\begin{abstract}
Danforth's short tail(Sd) mutant mice exhibit defects of the neural tube and other abnormalities, which are similar to the human vertebral anomalies, anal atresia, cardiac defects, tracheosophageal fistula and/or esophageal atresia, renal and radial abnormalities, and limb defects (VATER/VACTERL) association, including defects of the hindgut. $S d$ has been shown to underlie ectopic gene expression of murine Ptfla, which encodes pancreas-specific transcription factor $1 \mathrm{~A}$, due to the insertion of a retrotansposon in its 5 regulatory domain. In order to investigate the possible involvement of this gene in human VATER/VACTERL association and human neural tube defects (NTDs), a sequence analysis was performed. DNA samples from 103 patients with VATER/VACTERL and VATER/VACTERL-like association, all presenting with anorectal malformations, and 72 fetuses with NTDs, where termination of pregnancy had been performed, were included in the current study. The complete PTF1A coding region, splice sites and $1.5 \mathrm{~kb}$ of the 5 ' flanking promotor region was sequenced. However, no pathogenic alterations were detected. The results of the present study do not support the hypothesis that high penetrant mutations in these regions of PTF1A are involved in the development of human VATER/VACTERL
\end{abstract}

Correspondence to: Professor Michael Ludwig, Department of Clinical Chemistry and Clinical Pharmacology, University of Bonn, 25 Sigmund-Freud-Straße, Bonn D-53127, Germany

E-mail: mludwig@uni-bonn.de

*Contributed equally

Key words: anorectal malformation, Danforth's short tail mouse, neural tube defects, PTF1A gene, urogenital malformation, VATER/VACTERL association association or NTDs, although rare mutations may be detectable in larger patient samples.

\section{Introduction}

The Danforth's short tail (Sd) mouse, first reported in 1930, represents a semidominant spontaneous mutant, which is characterized by a broad range of anomalies, including neural tube and spinal defects, as well as anorectal, renal and urogenital malformations $(1,2)$. More recently, the molecular basis of $S d$ was elucidated by three groups who reported the insertion of a retrotansposon in the $5^{\prime}$ regulatory domain of the murine Ptfla gene that encodes pancreas-specific transcription factor 1A (3-5). As a consequence, and contrary to observations in wildtype littermates, $S d$ mice exhibited ectopic Ptfla expression in the notochord and hindgut at embryonic day (E) 8.5 to E9.5, which extended to the cloaca and mesonephros at E10.5, and to the pancreatic bud at E10.5 and E11.5 (4). The resultant phenotype of this $S d$ mutation mirrors the phenotype observed in the human vertebral anomalies, anal atresia, cardiac defects, tracheosophageal fistula and/or esophageal atresia, renal and radial abnormalities, and limb defects (VATER/VACTERL) association and in neural tube defects (NTDs).

The VATER/VACTERL association (MIM no. 192350), with a birth prevalence of 1 in 10,000 to 1 in 40,000 (6-8), refers to the non-random co-occurrence of the following component features (CFs): Vertebral defects (V); anorectal malformations (A); cardiac defects (C); tracheoesophageal fistula, with or without esophageal atresia (TE); renal malformations (R); and limb defects (L) (9). The condition is defined by the presence of at least three major CFs $(7,9)$. However, patients often present with additional features, in particular, urogenital anomalies. Although in the majority of cases, genetic determinants have yet to be identified, the observation of familial occurrence, an increase in the prevalence of CFs in first-degree relatives of affected individuals, higher concordance rates among monozygous twins, chromosomal (micro-)aberrations and the presence of single gene mutations 
in individuals with VATER/VACTERL association all point to the importance of genetic factors in the etiology of this non-random congenital multisystem defect (10).

NTDs (MIM no. 182940), affecting the precursor to the central nervous system, the brain and spinal cord, have a prevalence of 1 in 2,000 births (11). NTDs are hypothesized to arise from a complex combination of environmental and genetic factors, of which maternal folate intake is particularly important (12), as well as maternal pregestational obesity and diabetes $(13,14)$. In addition to the genes involved in folate metabolism (15), an increased risk of NTDs is associated with variants in the T-locus and the CCL2 gene, encoding chemokine monocyte chemoattractant protein $1(16,17)$. In rare cases, heterozygous mutations in the genes encoding Vang-like proteins 1 and 2, the coat protein (COPII) vesicle component gene, SEC 24B (encoding the transport protein Sec24B), and the protein fuzzy homolog $(F U Z Z Y)$ gene have been detected in familial and sporadic cases of NTD (18-21).

From the observations made in the $S d$ mouse, it was hypothesized that gain-of-function mutations in human $P T F 1 A$ or promoter variants may exert a similar effect to that of the mouse retrotransposon insertion. Lee et al (22) have shown, that specific single point mutations in mouse steroidogenic transcription factor (SF) 1 are involved in SF-1 sumoylation, by interfering with normal endocrine tissue development, thereby inducing ectopic expression of SF-1 target genes, such as sonic hedgehog. Therefore, the present study investigated the PTF1A gene and $1.5 \mathrm{~kb}$ of its $5^{\prime}$ flanking sequence in 103 patients exhibiting VATER/VACTERL features, with or without renal or urogenital defects, and in samples from 72 fetuses diagnosed with NTDs, in which termination of pregnancy had been performed.

\section{Materials and methods}

The present study was approved by the Ethics Committee of the Medical Faculty of the University of Bonn (Bonn, Germany), and written informed consent was obtained from all patients or parents prior to study entry.

Patients with VATER/VACTERL association. The sample contained 103 patients (33 females and 70 males) presenting with at least two CFs from the VATER/VACTERL spectrum (Table I). The age of the patients ranged from 3 to 54 years. Of these patients, 79 also exhibited renal and/or additional urogenital anomalies. As reported earlier, due to the recruitment procedure, all of these patients displayed anorectal malformations (23). All patients were of Central European origin and all reported an unremarkable family history. None of the patients investigated exhibited copy number variations in previous studies by this group (23-25) or mutations in TRAPl (26).

Fetuses with NTD. The present cohort of 72 fetuses following termination of pregnancy with NTD (37 females, 31 males and 4 of unknown sex) was sampled during this procedure, through the Department of Prenatal Medicine at the University of Bonn. Parents were of Central European origin in 60 of these cases. All except 4 reported an unremarkable family history. For 1 fetus, diagnosed with trisomy 18, NTD had
Table I. Number and phenotype of 103 patients investigated.

$\begin{array}{ll}\text { Phenotype No. of patients } & \text { Not }\end{array}$

VACTERL-like (two

10

cardinal features)

VACTERL-like including

renal/urogenital anomaly

VACTERL (at least

three cardinal features)

VACTERL including

renal/urogenital anomaly

VACTERL, vertebral anomalies, anal atresia, cardiac defects, tracheosophageal fistula and/or esophageal atresia, renal and radial abnormalities, and limb defects.

previously also been diagnosed in a maternal and a paternal cousin. In the second case, NTD was observed in a second cousin. Two women reported a previous pregnancy which had been affected by NTD. Table II lists further associated malformations observed in all the fetuses. One fetus was diagnosed with NTD and VATER/VACTERL association, and one fetus presented with additional bladder exstrophy.

DNA isolation. Blood or saliva samples were obtained from the patients and their parents, and for 97 cases both parents were available. Isolation of genomic DNA was conducted using a Chemagic Magnetic Separation Module I (Chemagen, Baesweiler, Germany) or, in the case of saliva samples, the Oragene DNA kit (DNA Genotek Inc., Kanata, ON, Canada).

Sequence analysis. Analysis of the two coding exons and $1,500 \mathrm{bp}$ of the $5^{\prime}$ untranslated promotor region (UTR) of the human PTFIA gene was performed using polymerase chain reaction (PCR). Primers for $P T F 1 A$ exons with their adjacent splice sites were (1F) 5'-GGGAGGGAGGGGCTCGGAC-3', (1R) 5'-TGGCAGTCAGCTCCCCCAGC-3'; and (2F) 5'-GGGGACGGTGGGGACTTGAAG-3', (2R) 5'-CATAGG GTGTTTGGAAGGTGGCC-3'. The 5'-UTR was amplified with the following primers: (5'-1F) 5'-TCTCAGAAGAAA CGCGCCCCG-3', (5'-1R) 5'-TCTAAGGCCCGTCCGAG CCC-3', (5'-2F) 5'-GGATAAGGGGGTGGCGGAATG-3' and (5'-2R) 5'-AGTTCCTAGGGGTGCGCGCC-3'. All primers were obtained from Metabion (Planegg, Germany). Blockcycler (Biometra T3000; Biometra, Göttingen, Germany) PCR was initiated by a 5 min denaturation step at $94^{\circ} \mathrm{C}$. The PCR program consisted of 35 cycles with a $30 \mathrm{sec}$ denaturation step at $94^{\circ} \mathrm{C}$, followed by a $30 \mathrm{sec}$ annealing step at $63^{\circ} \mathrm{C}$ (exon products) or at $68^{\circ} \mathrm{C}$ (promotor products) and a $180 \mathrm{sec}$ extension step (exon products) at $72^{\circ} \mathrm{C}$; for the promotor products, elongation time was $75 \mathrm{sec}$. A 7 min final extension step at $72^{\circ} \mathrm{C}$ completed the PCR. PCR-amplified DNA products were subjected to direct automated sequencing (3130X1 Genetic Analyzer, Applied Biosystems, Foster City, USA) according to the manufacturer's instructions. The two strands of each amplicon were sequenced and PCR primers also served as sequencing primers. PTFIA nucleotide and amino acid 
Table II. Phenotype of the fetuses with NTD.

Affected system

No. of fetuses $(\%)$

Myelomeningocele
Lumbosacral
Thoracic
Sacral
Frontal/occipital/cervical
Associated anomalies ${ }^{\mathrm{a}}$
Arnold-Chiari malformations
Hydrocephalus/ventriculo
Lower limb anomalies secon
Additional malformations
Further cerebral defects
Cardiac
Limb
Renal
Vertebral
Genitourinary

$1(1.4)$

an addition to myelomeningocele, fetuses may have had $>1$ of the associated anomalies and additional malformations listed. NTD, neural tube defects.

positions were numbered according to Ensembl transcript ID ENST00000376504 with the A of the start-methionine as no. 1 .

\section{Results}

Examination of all PTF1A exons and their adjacent splice sites did not reveal any likely causative sequence variant in the genes from the fetal or patient samples. A total of five heterozygous variants were detected, which were all unlikely to be causative for the occurrence of the VATER/VACTERL association or for NTDs. Three of these variants (non-synonymous coding in exon 2, rs7918487; non-coding in the 3'UTR, rs10828415 and rs149560393), deposited in dbSNP (Build 138), were frequently detected in our samples, and displayed similar frequencies as reported in the databases. A novel, heterozygous p.Gly90Ala substitution due to a c. $269 \mathrm{G}>\mathrm{C}$ transversion was found in one NTD fetal sample, where the patients declined to participate. It was therefore not possible to test the de novo occurrence of this variant. From validated protein sequences available, the amino acid position affected appears to be highly conserved among mammals (UniProtKB/Swiss-Prot entries G3UEX6, F7IDX3, G3T9V8, I3LMI3, Q9QX98 and Q64302, annotated for orangutan, marmoset, African elephant, pig, mouse and rat, respectively). However, a number of publically available prediction programs [Mutation Taster (http://www.mutationtaster.org/), MutPred (http://mutpred.mutdb.org/), PolyPhen-2 (http://genetics.bwh.harvard.edu/pph2/) and SIFT (http://sift. jcvi.org/www/SIFT_chr_coords_submit.html)] classified this amino acid change as benign.

A fifth, unreported heterozygous variant was detected in the 5'UTR of PTF1A in two cases with NTD, and one patient with VATER/VACTERL. This G-to-A transition at position -477 upstream of the start codon is located in a TFSEARCH-predicted (27) low-scored binding site for upstream stimulatory factor (USF), a ubiquitously expressed cellular transcription factor (28). However, comparison with the consensus binding sequence (NCACGTGN), revealed that this PTF1A variant only affects a variable position (gCACGcGg/a). Furthermore, the variant was transmitted from an unaffected mother in one NTD case and in the patient with VATER/VACTERL (in the second NTD case, the parents' samples were unavailable). Therefore, its involvement in the etiology of the respective phenotype remains unclear.

\section{Discussion}

The embryopathogenesis of VATER/VACTERL association and NTDs affects various different anatomical systems, namely the early central nervous system, and the skeletal, respiratory, cardiac, gastrointestinal, renal and urogenital systems. A number of the malformations appear early during human embryogenesis (16-30 days post conception), while others may arise up to 15 days later $(29,30)$. In accordance with these assumptions, the most recent findings in the $S d$ mouse provide a preliminary model, indicating how these anomalies may co-occur in a nonrandom fashion (3-5). Sd mice exhibited embryonic perturbance of the spatiotemporal expression pattern of a single gene, Ptfla, initially in the notochord and hindgut, then extending to the cloaca and mesonephros, and later to the pancreatic bud (4). Thus, the various interactions of transcription factor Ptfla affect multiple organs, interfering with the time window for their correct formation. As a consequence, the phenotype of the semidominant $S d$ mutation comprises defects of the neural tube and spinal column, the skeleton, and the renal, urogenital 
and anorectal system, mirroring the VATER/VACTERL association and NTDs.

Homozygous $S d$ mice are born alive, but die within $24 \mathrm{~h}$ of birth, whereas heterozygotes are less severely affected and are fertile, with some surviving into adulthood. Heterozygotes exhibit displaced kidneys, renal hypoplasia or renal unilateral agenesis, whereas homozygotes consistently present with spina bifida, bilateral renal agenesis, or severely malformed and dislocated kidneys. Bladder, urethra and external genitalia are absent in some homozygotes, while they are present in others. Heterozygotes frequently exhibit duplication of the ureteric buds $(2,31,32)$. In addition, whereas heterozygote $S d$ mice have no reported anorectal anomaly, homozygotes uniformly present with an imperforate anus $(2,31,32)$.

Previously in humans homozygous loss-of-function mutations in PTF1A have been identified in a total of four families with pancreatic and cerebellar agenesis (MIM: \#609069) (33-35). Although no pancreatic involvement has been reported in the $S d$ mouse, Ptfla null mice also lack a pancreas and die shortly after birth (36). In the present sequencing study, no causative PTF1A variant was observed in 103 patients with VATER/VACTERL association (Table I) or in the 72 fetuses with NTDs. The heterozygous p.Gly90Ala variant detected in one NTD sample affects an amino acid residue conserved in mammals. However, it was not predicted to be pathogenic in silico and, furthermore, it does not map to an important functional domain of the protein, meaning that it is unlikely to have a causative role.

As the complex temporospatial expression pattern of Ptfla has previously been reported to be controlled by $\geq 3$ regions, occupying $\sim 30 \mathrm{~kb}$ in the $3^{\prime}$ and $5^{\prime}$ flanking regions of the gene (37), it may be that a more extended sequence analysis may have identified causative variants in the two patient cohorts in the present study. Furthermore, genes targeted by PTFlA may be considered candidates for the VATER/VACTERL association or NTDs, and further studies, including larger numbers of patients, may identify rare causative mutations contributing to the manifestation of these defects. In this respect, the Currarino syndrome (MIM: \#176450), which consists of hemisacrum, anorectal malformations and presacral mass, may be caused by mutations affecting the transcription factor Motor neuron and pancreas homeobox protein 1 (MNX1/HLXB9), which is involved in pancreas development and function. As murine Mnx1 is a direct target of Ptfla (38), a common pathway, yet to be elucidated, may be affected in each of these non-random congenital multisystem defects.

\section{Acknowledgements}

Markus Draaken, Heiko Reutter, and Michael Ludwig are members of the 'Network for the Systematic Investigation of the Molecular Causes, Clinical Implications and Psychosocial Outcome of Congenital Uro-Rectal Malformations (CURE-Net)' which is supported by a research grant from the German Federal Ministry of Education and Research (Bundesministerium für Bildung und Forschung, BMBF; grant no. 01GM08107). Greta Große is supported by the BONFOR program of the University of Bonn (grant no. O-149.0104). Nirmala Gurung is supported by the Richard-Winter-Stiftung.
The authors would like to thank patients and their parents for their cooperation, and to acknowledge the German self-help organization for people with anorectal malformations (SoMA e.V.). The authors would also like to thank Pia Uerdingen for technical assistance.

\section{References}

1. Danforth CH: Developmental anomalies in a special strain of mice. Am J Anat 45: 275-287, 1930.

2. Dunn LC, Gluecksohn-Schoenheimer S and Bryson V: A new mutation in the mouse affecting spinal column and urogenital system. J Hered 31: 343-348, 1940.

3. Lugani F, Arora R, Papeta N, et al: A retrotransposon insertion in the 5' regulatory domain of Ptfla results in ectopic gene expression and multiple congenital defects in Danforth's short tail mouse. PLoS Genet 9: e1003206, 2013.

4. Semba K, Araki K, Matsumoto K, et al: Ectopic expression of Ptfla induces spinal defects, urogenital defects and anorectal malformations in Danforth's short tail mice. PLoS Genet 9: e1003204, 2013.

5. Vlangos CN, Siuniak AN, Robinson D, et al: Next-generation sequencing identifies the Danforth's short tail mouse mutation as a retrotransposon insertion affectin Ptfla expression. PLoS Genet 9: e1003205, 2013.

6. Khoury MJ, Cordero JF, Greenberg F, et al: A population study of the VACTERL association: Evidence for its etiologic heterogeneity. Pediatrics 71: 815-820, 1983.

7. Czeizel A and Ludányi I: An aetiological study of the VACTERL-association. Eur J Pediatr 144: 331-337, 1985.

8. Botto LD, Khoury MJ, Mastroiacovo P, et al: The spectrum of congenital anomalies of the VATER association: an international study. Am J Med Genet 71: 8-15, 1997.

9. Quan L and Smith DW: The VATER association. Vertebral defects, anal atresia, T-E fistula with esophageal atresia, radial and renal dysplasia: a spectrum of associated defects. J Pediatr 82: 104-107, 1973.

10. Reutter $\mathrm{H}$ and Ludwig M: VATER/VACTERL association: Evidence for the role of genetic factors. Mol Syndromol 4: 16-19, 2013.

11. Wallingford JB, Niswander LA, Shaw GM and Finnell RH: The continuing challenge of understanding, preventing and treating neural tube defects. Science 339: 1222002, 2013.

12. Blom HJ, Shaw GM, den Heijer M and Finnell RH: Neural tube defects and folate: Case far from closed. Nat Rev Neurosci 7: 724-731, 2006.

13. Shaw GM, Velie EM and Schaffer D: Risk of neural tube defect-affected pregnancies among obese women. JAMA 275: 1093-1096, 1996.

14. Sheffield JS, Butler-Koster EL, Casey BM, McIntire DD and Leveno KJ: Maternal diabetes mellitus and infant malformations. Obstet Gynecol 100: 925-930, 2002.

15. Mitchell LE, Adzick NS, Melchionne J, Pasquariello PS, Sutton LN and Whitehead AS: Spina bifida. Lancet 364: 1885-1895, 2004

16. Jensen LE, Barbaux S, Hoess K, Fraterman S, Whitehead AS and Mitchell LE: The human T locus and spina bifida risk. Hum Genet 115: 475-482, 2004.

17. Jensen LE, Etheredge AJ, Brown KS, Mitchell LE and Whitehead AS: Maternal genotype for the monocyte chemoattractant protein $1 \mathrm{~A}(-2518) \mathrm{G}$ promoter polymorphism is associated with the risk of spina bifida in offspring. Am J Med Genet A 140: 1114-1118, 2006.

18. Kibar Z, Torban E, McDearmid JR, et al: Mutations in VANGL1 associated with neural-tube defects. N Engl J Med 356: 1432-1437, 2007.

19. Lei YP, Zhang T, Li H, et al: VANGL2 mutations in human cranial neural-tube defects. N Engl J Med 362: 2232-2235, 2010.

20. Yang XY, Zhou XY, Wang QQ, et al: Mutations in the COPII vesicle component gene SEC24B are associated with human neural tube defects. Hum Mutat 34: 1094-1101, 2013.

21. Seo JH, Zilber Y, Babayewa S, et al: Mutations in the planar cell polarity gene, Fuzzy, are associated with neural tube defects in humans. Hum Mol Genet 20: 4324-4333, 2011.

22. Lee FY, Faivre EJ, Suzawa M, et al: Eliminating SF-1 (NR5A1) sumoylation in vivo results in ectopic hedgehog signaling and disruption of endocrine development. Dev Cell 21: 315-327, 2011. 
23. Schramm C, Draaken M, Bartels E, et al: De novo microduplication at 22q11.21 in a patient with VACTERL association. Eur J Med Genet 54: 9-13, 2011.

24. Dworschak GC, Draaken M and Marcelis C, et al: De novo 13q deletions in two patients with mild anorectal malformations as part of VATER/VACTERL and VATER/VACTERL-like association and analysis of EFNB2 in patients with anorectal malformations. Am J Med Genet A 161A: 3035-3041, 2013.

25. Hilger A, Schramm C, Pennimpede T, et al: De novo microduplications at 1q41,2q37.3 and 8q24.3 in patients with VATER/VACTERL association. Eur J Hum Genet 21: 1377-1382, 2013.

26. Saisawat $\mathrm{P}$, Kohl S, Hilger AC, et al: Whole exome resequencing reveals recessive mutations in TRAP1 in individuals with CAKUT and VACTERL association. Kidney Int 85: 1310-1317, 2014.

27. Heinemeyer T, Wingender E, Reuter I, et al: Databases on transcriptional regulation: TRANSFAC, TRRD and COMPEL. Nucleic Acids Res 26: 362-367, 1998.

28. Gregor PD, Sawadogo M and Roeder RG: The adenovirus major late transcription factor USF is a member of the helix-loop-helix group of regulatory proteins and binds to DNA as a dimer. Genes Dev 4: 1730-1740, 1990.

29. Dias MS and Partington M: Embryology of myelomeningocele and anencephaly. Neurosurg Focus 16: E1, 2004.

30. Stevenson RE and Hunter AG: Considering the embryopathogenesis of VACTERL association. Mol Syndromol 4: 7-15, 2013.
31. Gluecksohn-Schoenheimer S: The morphological manifestations of a dominant mutation in mice affecting tail and urogenital system. Genetics 28: 341-348, 1943.

32. Gluecksohn-Schoenheimer S: The embryonic development of mutants of the $S d$-strain in mice. Genetics 30: 29-38, 1945.

33. Sellick GS, Barker KT, Stolte-Dijkstra I, et al: Mutations in PTF1A cause pancreatic and cerebellar agenesis. Nat Genet 36: 1301-1305, 2004

34. Tutak E, Satar M, Yapicioğlu H, et al: A Turkish newborn infant with cerebellar agenesis/neonatal diabetes mellitus and PTF1A mutation. Genet Couns 20: 147-152, 2009.

35. Al-Shammari M, Al-Husain M, Al-Kharfy T and Alkuraya FS: A novel PTF1A mutation in a patient with severe pancreatic and cerebellar involvement. Clin Genet 80: 196-198, 2011.

36. Krapp A, Knöfler M, Ledermann B, et al: The bHLH protein PTF1-p48 is essential for the formation of the exocrine and the correct spatial organization of the endocrine pancreas. Genes Dev 12: 3752-3763, 1998.

37. Masui T, Swift GH, Hale MA, Meredith DM, Johnson JE and MacDonald RJ: Transcriptional autoregulation controls pancreatic Ptfla expression during development and adulthood. Mol Cell Biol 28: 5458-5468, 2008.

38. Thompson N,GésinaE,ScheinertP,BucherPandGrapin-Botton A: RNA profiling and chromatin immunoprecipitation-sequencing reveal that PTFIa stabilizes pancreas progenitor identity via the control of MNX1/HLXB9 and a network of other transcription factors. Mol Cell Biol 32: 1189-1199, 2012. 